\title{
Lung function, CT-scan and X-ray in upper airway obstruction due to thyroid goitre
}

\author{
C.F. Melissant*++, S.J. Smith*, R. Perlberger**, J. Verschakelen ${ }^{* \prime}$, \\ J-W.J. Lammers ${ }^{+}$, M. Demedts
}

Lung function, CT-scan and X-ray in upper airway obstruction due to thyroid goitre. C.F. Melissant, S.J. Smith, R. Perlberger, J. Verschakelen, J-W.J. Lammers, M. Demedts. CERS Journals Ltd 1994.

ABSTRACT: The purpose of this study was to assess the clinical reliability and to compare routine lung function tests (maximal flows and resistance) and radiological images (computed tomography (CT)-scan and X-ray) in upper airway obstruction.

We, therefore, performed these examinations prospectively in 28 female patients (aged $68 \pm 13 \mathrm{yrs}$ ) with a goitre and without pulmonary disorders. Lung function measurements consisted of maximum expiratory and inspiratory flow-volume curves and of airway resistance. CT-scans and X-rays were performed during apnoea at functional residual capacity (FRC).

Peak expiratory flow was $3.6 \pm 1.3 l \cdot \mathrm{s}^{-1}$ (i.e. $62 \pm 21 \%$ predicted); airway resistance was $0.38 \pm 0.14 \mathrm{kPa}$ (i.e. $149 \pm 58 \%$ pred); and specific conductance was $1.0 \pm 0.3 \mathrm{kPa}$ (i.e. $\mathbf{7 0} \pm 24 \%$ pred). Almost all lung function tests were significantly correlated with each other. On CT-scan the tracheal cross-sectional area at the zone of tracheal narrowing could be evaluated in 26 patients and was $58 \pm 17 \%\left(\mathrm{CT}_{1 / 2}\right)$ of the control area $2 \mathrm{~cm}$ above the carina $\left(\mathrm{CT}_{2}\right)$. On X-ray the sagittal and coronal tracheal diameters at the zone of narrowing could only be measured in 16 subjects and were $60 \pm 17 \%\left(\mathrm{X}-\mathrm{dia}_{1 / 2}\right)$ of the diameter at the control level. $\mathrm{CT}_{1 / 2}$ and $\mathrm{X}$-dia ${ }_{1 / 2}$ were significantly correlated to each other. No correlation was found between the lung function tests and the radiological indices except airway resistance and $\mathrm{CT}_{2}$.

Routine lung function and CT-scan do not provide comparable information on the degree of airway obstruction due to a goitre. Furthermore, X-ray of the trachea seems to be unreliable in visualizing upper airway obstruction.

Eur Respir J., 1994, 7, 1782-1787.

Large thyroid goitres generally grow intrathoracically and may cause upper airway obstruction (UAO) [1, 2], or even give rise to acute respiratory failure [2-4]. Routine detection and assessment of UAO is based mainly on radiology (computer tomography (CT)-scan and X-ray) and on lung function tests (spirometry with maximal flow-volume curves and resistance measurements) [5-9].

Comparative studies of tracheal size, lung function indices and body size in healthy subjects have been published; however, the findings were inconsistent [10-19]. Some authors found significant correlations between some indices of tracheal size and of lung or body size $[10,17,18]$; however the relevant functional indices could differ depending on sex [10], and there were, in particular, inconsistencies on which lung function index was best correlated with tracheal size [10, 17-19.] Other authors found very poor correlations between lung function indices and tracheal size [10-12], or between tracheal size and lung or body size [11-16], and they attributed this to the unequal growth pattern of the tracheobronchial tree and the lung parenchyma, which has been coined "dysanapsis" [12].
Dept of *Internal Medicine and **Radiology, Municipal Hospital Leyenburg, The Hague, The Netherlands. Depts of ${ }^{\dagger}$ Pulmonology and ${ }^{\dagger}$ Radiology, University Hospital Gasthuisberg, Leuven, Belgium. +Dept of Pulmonology University Hospital Utrecht, Utrecht, The Netherlands.

Correspondence: M. Demedts

Dienst Longziekten

Universitair Ziekenhuis Gasthuisberg

Herestraat 49

B-3000 Leuven

Belgium

Keywords: Airway resistance computed tomograpy scan cross-sectional area trachea maximal flow-voume curve thyroid goitre

upper airway obstruction

Recieved: January 12th 1994 Accepted after revision June 141994
We are unaware of published data on the relationship between changes in radiological, transverse tracheal dimensions and lung function abnormalities in UAO. It is, therefore, not clear which radiological or lung function measurement is clinically most useful i.e. most relevant and reliable in UAO.

The aim of the present study was to evaluate and to compare routinely applicable lung function tests and radiological changes in patients with UAO due to a goitre.

\section{Patients and methods}

\section{Patients}

Twenty-eight female patients (age $68 \pm 13$ yrs) with an euthyroid multinodular goitre were evaluated prospectively. The diagnosis had been made by measurement of thyroid stimulating hormone (TSH) and thyroxine (T4) in combination with ultrasonography and/or nuclear imaging of the thyroid.

Patients with a history or clinical evidence of chronic obtructive pulmonary disease (COPD), or asthma or 
of other pulmonary disorders, including obstructive sleep apnoea syndrome, and smokers were excluded. The selected patients were divided into three subgroups on the basis of the maximal expiratory flow-volume (MEFV) curve and maximal inspiratory flow-volume (MIFV) curve, as described previously $[5,20]$ : the subgroup with a variable extrathoracic obstruction $(n=6)$ was characterized by an inspiratory plateau on the MIFV curve and a maximal mid-expiratory flow/maximal mid inspiratory flow $\left(\mathrm{MEF}_{50} / \mathrm{MIF}_{50}\right)$ ratio of more than 1.1; in the subgroup with a fixed obstruction $(n=11)$, both inspiratory and expiratory flow plateaus were present with a $\mathrm{MEF}_{50} / \mathrm{MIF}_{50}$ ratio of $0.9-1.1$; the subgroup with a variable intrathoracic obstruction $(n=11)$ presented an expiratory flow plateau with a $\mathrm{MEF}_{50} / \mathrm{MIF}_{50}$ ratio of below 0.9 .

\section{Methods}

The FEV ${ }_{1}$, forced expiratory volume in one second $\left(\mathrm{FIV}_{1}\right)$ and the MEFV and MIFV curves were recorded at the mouth with a Lilly-type pneumotachograph and integrator. The airway resistance (Raw) was measured at functional residual capacity (FRC) in a constant-volume plethysmograph (Jaeger, FRG) as the chord slope between inspiratory and expiratory flows at $0.5 \mathrm{l} \cdot \mathrm{s}^{-1}$; the specific airway conductance (sGaw) was calculated as the reciprocal of Raw divided by thoracic gas volume. Residual volume (RV) and total lung capacity (TLC) were measured by body plethysmography (Jaeger, FRG). The lung function tests were carried out according to the European Respiratory Society (ERS) recommendations [21, 22] and were expressed in absolute values and as a percentage of the reference values of the European Community for Coal and Steel (ECCS) [21], except for Raw and specific airway conductance (sGaw), which were expressed as a percentage of the reference values of AMREIN et al. [23].

Radiological data were obtained by CT-scan (General Electric 8800, USA) and by X-ray of the trachea, both at resting end expiratory volume and were analysed by the research team (RP and JV). CT-measurements were made with the patient in supine position; scans were obtained at $10 \mathrm{~mm}$ intervals from the level of the mandibula to the carina, with a $5.76 \mathrm{~s}$ scanning time. Transverse diameters were measured in two perpendicular directions (coronal and sagittal), and cross-sectional areas were measured with the help of the software programme of General Electric (ROI). Minimal cross-sectional area $\left(\mathrm{CT}_{1}\right)$ at the level of the obstruction was compared with the crosssectional area $2 \mathrm{~cm}$ above the carina $\left(\mathrm{CT}_{2}\right)$, which was used as reference. From these values the ratio of $\mathrm{CT}_{1}$ to $\mathrm{CT}_{2}\left(\mathrm{CT}_{1 / 2}\right)$ was calculated.

$\mathrm{X}$-rays of the trachea were made in standing subjects in anteroposterior and lateral position. From these, transverse diameters in coronal and sagittal plane were measured at the level of the obstruction; the mean of both diameters was called X-dia ${ }_{1}$. Maximal transverse diameters in both planes were measured $2 \mathrm{~cm}$ above the carina. When this level was not well-visualized, then the maximal diameters were measured at a level where the tracheal diameter remained the same over at least 2 $\mathrm{cm}$; the mean of both diameters was called maximal transverse diameter $\left(\mathrm{X}\right.$-dia $\left.{ }_{2}\right)$. The ratio $\mathrm{X}$-dia do $_{1} \mathrm{X}$-dai ${ }_{2}$ was calculated $\left(\mathrm{X}-\mathrm{dia}_{1 / 2}\right)$. Also the tracheal crosssectional areas were calculated at both levels ( $\min =\mathrm{X}$ $\operatorname{area}_{1} ; \max =\mathrm{X}-\mathrm{area}_{2}$ ) assuming an elliptical shape. The percentage reduction in cross-sectional area $\left(\mathrm{X}\right.$-area $\left.\mathrm{a}_{1 / 2}\right)$ was calculated. A magnification factor of 1.25 was used for the dimensional amplification. The reasons for using the tracheal dimensions at $2 \mathrm{~cm}$ above the carina as a reference were: 1) reference values of healthy control subjects are unreliable because interindividual differences are large (at least 50\%) and not clearly related to anthropometric data [10-19]; and 2) the intra-individual variations between transverse dimensions at different levels of the trachea are quite small. Although the tracheal diameters at the level $2 \mathrm{~cm}$ above the carina are about $10 \%$ greater than in the middle part, this relationship is highly reproducible between subjects [24, 25].

\section{Statistics}

Means \pm 1 SD were calculated. Correlation coefficients were obtained by the least square method and linear regressions were calculated and evaluated by Student's t-tests. Analyses of variance were applied, and a Duncan test was carried out to determine the significance of differences between the three subgroups. The level of significance was set at $\mathrm{p}<0.05$.

Table 1. - Anthropometric data and lung function indices $(\mathrm{n}=28$ females $)$

\begin{tabular}{|c|c|c|}
\hline & mean & $\%$ pred \\
\hline Age yrs & $68 \pm 13$ & \\
\hline Weight $\mathrm{kg}$ & $67 \pm 17$ & \\
\hline Length $\mathrm{cm}$ & $162 \pm 6$ & \\
\hline $\mathrm{VC} l$ & $2.6 \pm 0.7$ & $97 \pm 19$ \\
\hline TLC $l$ & $4.8 \pm 0.8$ & $97 \pm 14$ \\
\hline $\mathrm{FEV}_{1} l$ & $1.7 \pm 0.6$ & $82 \pm 23$ \\
\hline $\mathrm{FIV}_{1} l$ & $2.0 \pm 0.7$ & $99 \pm 24$ \\
\hline $\mathrm{PEF} \quad l \cdot \mathrm{s}^{-1}$ & $3.6 \pm 1.3$ & $62 \pm 21$ \\
\hline $\mathrm{MEF}_{50} l \cdot \mathrm{s}^{-1}$ & $1.9 \pm 0.8$ & $56 \pm 21$ \\
\hline $\mathrm{MIF}_{50} l \cdot \mathrm{s}^{-1}$ & $2.1 \pm 0.9$ & $57 \pm 24$ \\
\hline Raw $\mathrm{kPa} \cdot l^{-1} \cdot \mathrm{s}$ & $0.38 \pm 0.14$ & $149 \pm 58$ \\
\hline Gaw $l \cdot \mathrm{kPa}^{-1} \cdot \mathrm{s}^{-1}$ & $3.1 \pm 1.0$ & \\
\hline $\mathrm{sGaw} \mathrm{kPa}^{-1} \cdot \mathrm{s}^{-1}$ & $1.0 \pm 0.3$ & $70 \pm 24$ \\
\hline $\mathrm{MEF}_{50} / \mathrm{MIF}_{50} l \cdot \mathrm{s}^{-1} / l \cdot \mathrm{s}^{-1}$ & $1.0 \pm 0.6$ & \\
\hline$\% / \%$ & $1.1 \pm 0.6$ & \\
\hline $\mathrm{PEF} / \mathrm{MEF}_{50} l \cdot \mathrm{s}^{-1} / l \cdot \mathrm{s}^{-1}$ & $2.0 \pm 0.8$ & \\
\hline$\% / \%$ & $1.2 \pm 0.5$ & \\
\hline $\mathrm{FEV}_{1} / \mathrm{PEF} \mathrm{ml} / l \cdot \mathrm{min}^{-1}$ & $8.2 \pm 1.8$ & \\
\hline$\% \%$ & $1.4 \pm 0.3$ & \\
\hline $\mathrm{MEF}_{50} / \mathrm{Gaw} l \cdot \mathrm{s}^{-1} / \mathrm{kPa}^{-1} \cdot l \cdot \mathrm{s}^{-1}$ & $0.7 \pm 0.3$ & \\
\hline$\% / \mathrm{kPa}^{-1} \cdot l \cdot \mathrm{s}^{-1}$ & $20.3 \pm 7.1$ & \\
\hline
\end{tabular}

Data are presented as mean \pm SD. VC: vital capacity; TLC: total lung capacity; $\mathrm{FEV}_{1}$ : forced expiratory volume in one second; $\mathrm{FIV}_{1}$ : inspiratory volume in one second; PEF; peak expiratory flow; $\mathrm{MEF}_{50}$ and $\mathrm{MIF}_{50}$ : maximal expiratory and inspiratory flows at 50\% VC; Raw: airway resistance; Gaw: airway conductance; sGaw: specific airway conductance. Predicted values are from [21] and [22]. For the ratios the same units are used as in Melissant et al. [5]. 
Table 2. - Computer tomography (CT)-scan and X-ray data

\begin{tabular}{|c|c|c|}
\hline $\begin{array}{l}\text { CT-scan } \\
\text { Diameters }\end{array}$ & & $\mathbf{n}$ \\
\hline Min. sagittal $\mathrm{cm}$ & $1.25 \pm 0.19$ & 26 \\
\hline coronal $\mathrm{cm}$ & $0.85 \pm 0.20$ & 26 \\
\hline Max. sagittal cm & $1.70 \pm 0.27$ & 26 \\
\hline coronal $\mathrm{cm}$ & $1.46 \pm 0.36$ & 26 \\
\hline Cross-sectional areas & & \\
\hline Min. $\left(\mathrm{CT}_{1}\right) \mathrm{cm}^{2}$ & $1.4 \pm 0.4$ & 26 \\
\hline $\operatorname{Max} .\left(\mathrm{CT}_{2}\right) \mathrm{cm}^{2}$ & $2.4 \pm 0.6$ & 26 \\
\hline Ratio $\left(\mathrm{CT}_{1 / 2}\right) \%$ & $58 \pm 17$ & 26 \\
\hline X-ray & & \\
\hline Diameters & & \\
\hline Min. sagittal cm & $1.15 \pm 0.33$ & 17 \\
\hline coronal $\mathrm{cm}$ & $0.93 \pm 0.35$ & 22 \\
\hline mean $\left(X-\right.$ dia $\left._{1}\right) \mathrm{cm}$ & $0.96 \pm 0.32$ & 16 \\
\hline Max. sagittal $\mathrm{cm}$ & $1.73 \pm 0.34$ & 17 \\
\hline coronal $\mathrm{cm}$ & $1.64 \pm 0.37$ & 22 \\
\hline mean $\left(\mathrm{X}-\mathrm{dia}_{2}\right) \mathrm{cm}$ & $1.70 \pm 0.40$ & 16 \\
\hline Ratio sagittal \% & $67 \pm 15$ & 17 \\
\hline coronal \% & $58 \pm 22$ & 22 \\
\hline$\underset{\text { mean X-dia }}{\text { mross-sectional areas }} \%$ & $60 \pm 17$ & 16 \\
\hline $\begin{array}{l}\text { Cross-sectional areas } \\
\text { Min. }\left(\mathrm{X} \text {-area } \mathrm{cm}_{1} \mathrm{~cm}^{2}\right.\end{array}$ & & \\
\hline $\begin{array}{l}\text { Min. }\left(X-\text { area }_{1}\right) \quad \mathrm{cm}^{2} \\
\text { Max }(\mathrm{X}-\mathrm{area}) \mathrm{cm}^{2}\end{array}$ & $0.91 \pm 0.5$ & 51 \\
\hline Max. $\left(\mathrm{X}-\mathrm{area}_{2}\right) \mathrm{cm}^{2}$ & $2.42 \pm 0.93$ & 16 \\
\hline Ratio $\left(\mathrm{X}\right.$-area $\left.\mathrm{a}_{1 / 2}\right) \%$ & $39 \pm 23$ & 16 \\
\hline
\end{tabular}

Minimal (Min.) diameters and cross-sectional areas were measured at the level of the obstruction. Maximal (Max.) diameters and cross-sectional areas were measured $2 \mathrm{~cm}$ above the carina (or alternatively for the X-ray at a level close to it where tracheal size did not change over a length of $2 \mathrm{~cm}$ ). Coronal: laterolateral; sagittal: anteroposterior.
Table 3. - Correlation coefficients between various lung function indices

\begin{tabular}{lcccccc}
\hline & FEV $_{1}$ & PEF & MEF $_{50}$ & FIV $_{1}$ & MIF $_{50}$ & Raw \\
\hline PEF & $0.73^{*}$ & - & - & - & - & - \\
MEF $_{50}$ & $0.77^{*}$ & $0.57^{+}$ & - & - & - & - \\
FIV $_{1}$ & $0.65^{\dagger}$ & $0.71^{*}$ & 0.38 & - & - & - \\
MIF $_{50}$ & $0.63^{*}$ & $0.56^{+}$ & $0.39^{\dagger}$ & $0.53^{+}$ & - & - \\
Raw & $-0.58^{+}$ & -0.33 & $-0.49^{+}$ & $-0.52^{\dagger}$ & $-0.53^{\dagger}$ & - \\
sGaw $^{+}$ & $0.64^{+}$ & 0.24 & $0.62^{+}$ & 0.25 & 0.32 & $0.81^{*}$ \\
\hline
\end{tabular}

For abbreviations see legend to table 1 . Values are in $\%$ predicted, yet results are very similar when absolute values are used. ${ }^{+}$: $\mathrm{p}<0.05 ;{ }^{*}$ : $\mathrm{p}<0.01$.

\section{Results}

The anthropometric and lung function data of the total group are given in table 1 . The changes in the dynamic expiratory and inspiratory indices are not uniform: peak expiratory flow (PEF), $\mathrm{MEF}_{50}$ and $\mathrm{MIF}_{50}$ are reduced to about $60 \%$ of the predicted values, whereas $\mathrm{FEV}_{1}$ and, in particular FIV 1 are still within normal limits. Static lung volumes are normal, as can be expected. The values of the ratios of some dynamic lung function indices $\left(\mathrm{MEF}_{50} / \mathrm{MIF}_{50}, \mathrm{FEV}_{1} / \mathrm{PEF}, \mathrm{PEF} / \mathrm{MEF}_{50}, \mathrm{MEF}_{50} / \mathrm{Gaw}\right)$ fall within the ranges expected in UAO $[5,8,9]$.

The radiological data are depicted in table 2. On CTscan, the minimal tracheal lumen is $58 \pm 17 \%$ of the "reference" (or maximal) cross-sectional area; on X-ray the minimal diameter is $60 \pm 17 \%$ of the "reference" diameter, but the ratio of the calculated cross-sectional areas

Table 4. - Anthropometric and radiological data in the three UAQ subgroups: variable extrathoracic (E), fixed (F) and variable intrathoracic (I)

\begin{tabular}{|c|c|c|c|c|}
\hline & E & $\mathrm{F}$ & I & Duncan test \\
\hline Patients $\mathrm{n}$ & 6 & 11 & 11 & \\
\hline Age yrs & $59 \pm 12$ & $70 \pm 12$ & $71 \pm 14$ & EFI \\
\hline Weight $\mathrm{kg}$ & $80.8 \pm 24.8$ & $62.2 \pm 7.9$ & $64.2 \pm 12.7$ & E-FI \\
\hline Length $\mathrm{cm}$ & $163.0 \pm 7.2$ & $161.9 \pm 4.7$ & $160.3 \pm 7.6$ & EFI \\
\hline $\mathrm{MEF}_{50} / \mathrm{MIF}_{50} \quad l \cdot \mathrm{s}^{-1} / l \cdot \mathrm{s}^{-1}$ & $1.9 \pm 0.6$ & $1.0 \pm 0.1$ & $0.6 \pm 0.2$ & E-F-I \\
\hline TLC $\%$ pred & $88.6 \pm 14.5$ & $97.3 \pm 11.9$ & $109.0 \pm 5.3$ & EF-FI \\
\hline $\mathrm{FEV}_{1} \%$ pred & $72.7 \pm 19.7$ & $88.4 \pm 21.1$ & $80.5 \pm 26.4$ & EFI \\
\hline $\mathrm{FIV}_{1} \%$ pred & $86.2 \pm 19.4$ & $97.9 \pm 27.2$ & $103.4 \pm 22.1$ & EFI \\
\hline PEF \% pred & $53.3 \pm 22.7$ & $63.6 \pm 22.2$ & $64.6 \pm 18.7$ & EFI \\
\hline $\mathrm{MEF}_{50} \%$ pred & $51.9 \pm 21.7$ & $67.9 \pm 19.6$ & $45.7 \pm 18.1$ & EF-FI \\
\hline $\mathrm{MIF}_{50} \%$ pred & $27.4 \pm 10.7$ & $57.9 \pm 17.4$ & $71.9 \pm 20.6$ & E-FI \\
\hline Raw $\mathrm{kPa} \cdot l^{-1} \cdot \mathrm{s}$ & $0.48 \pm 0.20$ & $0.33 \pm 0.10$ & $0.32 \pm 0.10$ & EF-FI \\
\hline sGaw $\mathrm{kPa}^{-1} \cdot \mathrm{s}^{-1}$ & $1.0 \pm 0.5$ & $1.1 \pm 0.3$ & $1.0 \pm 0.3$ & EFI \\
\hline \multicolumn{5}{|l|}{$\mathrm{PEF} / \mathrm{MEF}_{50}$} \\
\hline$\% / \%$ & $1.1 \pm 0.4$ & $0.9 \pm 0.3$ & $1.6 \pm 0.6$ & EF-I \\
\hline$l \cdot \mathrm{s}^{-1} / l \cdot \mathrm{s}^{-1}$ & $1.8 \pm 0.6$ & $1.6 \pm 0.4$ & $2.7 \pm 1.0$ & EF-I \\
\hline \multicolumn{5}{|l|}{$\mathrm{FEV}_{1} / \mathrm{PEF}$} \\
\hline$\% / \%$ & $1.5 \pm 0.3$ & $1.5 \pm 0.3$ & $1.3 \pm 0.4$ & EFI \\
\hline $\mathrm{ml} / l \cdot \min ^{-1}$ & $9.5 \pm 2.7$ & $8.5 \pm 1.2$ & $7.2 \pm 1.7$ & EF-FI \\
\hline \multicolumn{5}{|l|}{$\mathrm{MEF}_{50} / \mathrm{Gaw}$} \\
\hline$\% / \mathrm{kPa}^{-1} \cdot l \cdot \mathrm{s}^{-1}$ & $22.7 \pm 7.0$ & $21.9 \pm 8.4$ & $15.8 \pm 4.0$ & EFI \\
\hline$l \cdot \mathrm{s}^{-1} / \mathrm{kPa}^{-1} \cdot l \cdot \mathrm{s}^{-1}$ & $0.9 \pm 0.3$ & $0.8 \pm 0.3$ & $0.6 \pm 0.1$ & EFI \\
\hline $\mathrm{CT}_{1} \mathrm{~cm}^{2}$ & $1.4 \pm 0.3$ & $1.3 \pm 0.3$ & $1.5 \pm 0.5$ & EFI \\
\hline $\mathrm{CT}_{2} \mathrm{~cm}^{2}$ & $2.7 \pm 0.6$ & $2.5 \pm 0.6$ & $2.3 \pm 0.6$ & EFI \\
\hline $\mathrm{CT}_{1 / 2}^{2} \%$ & $54 \pm 14$ & $54 \pm 16$ & $64 \pm 19$ & EFI \\
\hline $\mathrm{X}-$ dia $_{1} \mathrm{~cm}$ & $1.0 \pm 0.5$ & $0.9 \pm 0.5$ & $1.1 \pm 0.3$ & EFI \\
\hline $\mathrm{X}$-dia, $\mathrm{cm}$ & $1.8 \pm 0.5$ & $1.7 \pm 0.6$ & $1.6 \pm 0.4$ & EFI \\
\hline$X-\operatorname{dia}_{1 / 2} \%$ & $55 \pm 23$ & $50 \pm 13$ & $70 \pm 13$ & EFI \\
\hline
\end{tabular}

Data are presented as mean \pm SD. For abbreviations see legend to table 1. Groups separated by dash in Duncan test differ significantly $(\mathrm{p}<0.05)$. 
is only $39 \pm 23 \%$. The length of the obstruction on $\mathrm{X}$ ray is $4.3 \pm 1.5 \mathrm{~cm}$.

In table 3 , the correlations between the lung function indices are presented. As could be expected, most lung function indices are significantly correlated to each other.

For the radiological data, no significant correlations are found with the anthropometric data except between $\mathrm{X}-\mathrm{dia}_{2}$ (maximal diameter) and body height ( $\mathrm{r}=0.51$; $\mathrm{p}<0.05$ ). Also, between X-ray and CT-scan significant correlations are only found between $\mathrm{X}-\mathrm{dia}_{2}$ and $\mathrm{CT}_{2}$ $(\mathrm{r}=0.54, \mathrm{p}<0.05)$ and between $\mathrm{X}-\mathrm{dia}_{1 / 2}$ and $\mathrm{CT}_{1 / 2}(\mathrm{r}=0.50$, $\mathrm{p}<0.05)$.

The correlations between the lung function indices and the radiologic parameters are not significant, except between $\mathrm{CT}_{2}$ and Raw or sGaw ( $\mathrm{r}=0.51$ and $\mathrm{r}=0.60$ respectively; $\mathrm{p}<0.05)$.

Table 4 presents the data obtained by subdividing the patients into three subgroups (variable extrathoracic obstruction; fixed obstruction; and variable intrathoracic obstruction) based on the $\mathrm{MEF}_{50} / \mathrm{MIF}_{50}$ ratio. Variable extrathoracic obstruction is significantly different from both other groups for weight and $\mathrm{MIF}_{50}$; it is different from variable intrathoracic obstruction for TLC, $\mathrm{MEF}_{50}$, Raw and $\mathrm{FEV}_{1} / \mathrm{PEF}$. Variable intrathoracic obstruction is different from the two other groups for $\mathrm{PEF} / \mathrm{MEF}_{50}$. The lung function abnormalities tend to be most pronounced in variable extrathoracic obstruction and least pronounced in variable intrathoracic obstruction. No differences are found between the three subgroups for the CT-scan and X-ray indices, although the minimal diameters, the minimal cross-sectional areas and the ratios tend to be larger in variable intrathoracic obstruction.

\section{Discussion}

The main purpose of this study was to search for simple but clinically useful and relevant functional and radiologic indices, which reliably reflect the degree of tracheal narrowing in UAO. Furthermore, we were interested in the correlation between changes in lung function indices (measured during large manoeuvres and during quiet breathing) and changes in radiological dimensions of the trachea (cross-sectional area and transverse diameters measured by CT-scan and X-ray) in UAO.

We, therefore, studied 28 female patients with UAO due to thyroid goitre. The findings were that pulmonary function tests showed a reduction in maximal flows (PEF, $\left.\mathrm{MEF}_{50}, \mathrm{MIF}_{50}\right)$ to about $60 \%$ predicted, and in sGaw to $70 \%$ predicted; the radiologic evaluation showed a reduction in cross-sectional area on CT-scan and in transverse diameters of the trachea on X-ray to about $60 \%$. Whilst most lung function data were significantly correlated with each other, this was not the case for the radiological changes at the level of the UAO. In addition, no correlation was found between the abnormalities in pulmonary function tests and in radiological dimensions.

Some methodological and technical aspects of the study need an explanation. Firstly, lung function changes were related to the reference values of healthy control populations [21-23], whilst the radiological changes were related to a reference area in the trachea of each subject. The reason for this is that tracheal transverse dimensions, in contrast to lung function data, are not well-correlated with anthropometric data, such as age, sex and height, and in addition show wide interindividual variations (of more than $50 \%$ despite comparable anthropometric characteristics) [10-19]. Therefore, expressing changes of tracheal dimensions in percentage of the values in a control population is not useful. Studies comparing airway size with lung or body size have, indeed, not yielded consistent results and several of these studies were unable to find any significant correlation [10-19]. The latter was attributed to dysanapsis i.e. the apparently unequal growth pattern of the tracheobronchial tree and the lung parenchyma [12]. On the other hand, the transverse dimensions at different levels of the trachea vary less than $10 \%$ from each other, except at the glottis and the carina $e . g$. the difference between the level at $2 \mathrm{~cm}$ above the carina and the middle part of the trachea is $10 \%$ at the most $[24,25]$. Since, in our patients, the trachea at the level of $2 \mathrm{~cm}$ above the carina was always at a distance from the narrowed area and was well-visualized in most subjects, it was used as reference zone. The tracheal dimensions measured by CT-scan and X-ray in our study were grossly comparable with the data from the literature [10, 13-16, 19], although BROOKs et al. [10] obtained somewhat smaller values. In agreement with most of these studies, we found no significant correlation between the normal tracheal dimensions (in our study measured at the unaffected level $2 \mathrm{~cm}$ above the carina) and the anthropometric data (such as height and age) or the lung volumes (such as spirometry or maximal flows, expressed in absolute values). There was, however, a significant correlation between the tracheal crosssectional area at $2 \mathrm{~cm}$ above the carina $\left(\mathrm{CT}_{2}\right)$ and Raw.

Secondly, it was our purpose to use radiological and lung function methods that are routine techniques. Indeed, spirometry with maximal flow volume curves, body plethysmography, CT-scan and X-rays are readily available in a clinical set-up.

Among the lung function indices obtained during forced manoeuvres, the maximal flow-volume loops, in particular, were very informative to characterize the UAO [5, 20] and to categorize it into several subgroups (fixed, variable extrathoracic, or variable intrathoracic). Several ratios (i.e.PEF/MEF $\mathrm{ME}_{50}<2.1 \% / \%$ or $\mathrm{FEV} / \mathrm{PEF}>8 \mathrm{ml} / l \cdot \mathrm{min}^{-1}$ ) used to differentiate UAO from COPD and asthma $[8,9,26$, 27] were also indicative of UAO in our patients. In addition, the $\mathrm{MEF}_{50} / \mathrm{Gaw}$ (i.e. the ratio of the airway patency during a forced expiration to that during quiet breathing) was increased to $20.3 \pm 7.1 \% / \mathrm{kPa}^{-1} \cdot l \cdot \mathrm{s}^{-1}$ or $0.7 \pm 0.3$ $l \cdot \mathrm{s}^{-1} / \mathrm{kPa}^{-1} \cdot l \cdot \mathrm{s}^{-1}$ which we have previously shown to be an index of UAO [5]. Although the maximal flow-volume indices and the derived ratios are very sensitive for describing UAO, and although most lung function tests are significantly correlated with each other, it remains to be determined which is the best lung function test to reflect the degree of UAO or the severity of the functional impairment in UAO. $\mathrm{FEV}_{1}$ is known to give a gross underestimation. PEF is probably less accurate due to its effort dependence. $\mathrm{MEF}_{50}$ and $\mathrm{MIF}_{50}$ are apparently 
reliable reflections of the airway narrowing during the forced manoeuvre, but this may differ from the situation during quiet breathing, due to dynamic compression or collapse of the airways. Measurements during quiet breathing are probably more relevant as a reflection of the functional impairment during daily life, and, therefore, we propose that Raw, Gaw or sGaw might be the most appropriate tests. Indeed, several studies have shown that among the lung function tests, airway resistance is best correlated with tracheal dimensions in healthy women $[10,17]$. In our study airway resistance was the only pulmonary function test which was significantly correlated with a radiologic index; however, not at the narrowed level of the trachea but at the level $2 \mathrm{~cm}$ above the carina. Clearly, further studies are needed to determine the clinically most relevant pulmonary function test.

Concerning the comparison between the two radiological techniques, only the correlation between the tracheal narrowing measured with CT-scan $\left(\mathrm{CT}_{1 / 2}\right)$ and X-ray $\left(\mathrm{X}-\mathrm{dia}_{1 / 2}\right)$ was significant. One could speculate that the fact that X-ray is done in upright posture and CT-scan in supine posture may be an explanation for the poor correlation between the two techniques. The CT-scan allowed the tracheal cross-sectional area to be measured at the level of the UAO in 26 of the 28 subjects, whilst the X-ray was evaluable in only 16 subjects. For this reason, CT-scan seems to be more appropriate than Xray to evaluate the degree of UAO. It should be noted that the percentage narrowing was quite different between the two methods: the cross-sectional area at the level of the UAO estimated from the X-ray was $39 \%$ of the reference area, whilst the CT-scan measured a value of $58 \%$, which is more in agreement with the value of about $60 \%$ predicted obtained with the lung function tests.

The correlations between most lung function indices and the radiological measurements were weak. There are several explanations for this. With the exception of Raw (and implicitly Gaw and sGaw), the dynamic lung function indices were measured during large, forced manoeuvres. Furthermore, the radiological measurements were made at resting end-expiratory volume, whereas the trajectory of the large dynamic manoeuvres included the whole VC. It is known that the diameter of the tracheal lumen varies with the phase of respiration and with lung volume, being largest at TLC and smallest at RV [19]. Finally, the geometrically complex structure of the upper airways is subject to considerable variability with changes in position [28]. In this study, lung function variables and tracheal X-rays were obtained with the patient in upright sitting position whereas for the CT-scan the patient was supine.

In conclusion, this study shows that routinely available radiographic methods did not offer a significant contribution to the evaluation of the impairment in patients with UAO. We agree with SHEPARD et al. [29], that future studies on anatomical, pathological and functional relationships in UAO should preferably consider the simultaneous measurement of lung function and radiological imaging. Fast CT-scanning gives a clear dynamic imaging in transverse orientation and includes very transient phenomena [30]. Nevertheless, at present, this type of CT-scan is not widely available, so that, in general, its value remains experimental rather than routine. Also, the acoustic reflection technique might give more insight in the pathophysiological changes in UAO $[10,19,31,32]$. Meanwhile, we can only conclude that in our group of patients with a goitre, both routine lung function tests and CT-scan depict the UAO although both techniques are not well correlated to each other. X-ray of the trachea would not visualize the obstruction in almost half of the subjects and is, therefore, not reliable.

Acknowledgements: The authors wish to thank A. Hoek, G.J. Kieft, W.M.C. Mallens (Municipal Hospital Leyenburg, The Hague, The Netherlands) and J. Romont (University Hospital Leuven, Pellenberg, Belgium) for their contribution to this study.

\section{References}

1. Jauregui R, Liker ES, Bayley A. Upper airway obstruction in euthyroid goiter. J Am Med Assoc 1977; 238: 2163-2166.

2. Shambaugh GE, Seed R, Korn A. Airway obstruction in substernal goiter: clinical and therapeutic implications. J Chron Dis 1973; 26: 737-743.

3. Segall D. Endothoracic goiter. Arch Intern Med 1968; 121: 353-355.

4. Shaha A, Alfonso A, Jaff BM. Acute airway distress due to thyroid pathology. Surg 1987; 102: 1068-1074.

5. Melissant CF, Van Noord JA, Van De Woestijne KP, Demedts $M$. Comparison of dynamic lung function indices during forced and quiet breathing in upper airway obstruction, asthma and emphysema. Chest 1990; 98: 77-83.

6. Miller RD, Hyatt RE. Obstructing lesions of the larynx and the trachea: clinical and physiological characteristics. Mayo Clin Proc 1969; 44: 145-161.

7. Shim C, Corro P, Park SS, Williams MH. Pulmonary function studies in patients with upper airway obstruction. Am Rev Respir Dis 1972; 106: 233-238.

8. Yernault JC, Englert M, Sergysels R, De Coster A. Upper airway stenosis; a physiological study. Am Rev Respir Dis 1973; 108: 996-1000.

9. Rotman HH, Liss HP, Weg JG. Diagnosis of upper airway obstruction by pulmonary function testing. Chest 1975; 68: 796-799.

10. Brooks LJ, Byard PJ, Helms RC, Fouke JM, Strohi KP. Relationship between lung volume and tracheal area as assessed by acoustic reflection. J Appl Physiol 1988; 64: 1050-1054.

11. Castile RG, Hyatt RE, Rodarte JR. Determinants of maximal expiratory flow and density dependence in normal humans. J Appl Physiol: Respirat Environ Exercise Physiol 1980; 49: 897-904.

12. Mead J. Dysanapsis in normal lungs assessed by the relationship between maximum flow, static recoil, and vital capacity. Am Rev Respir Dis 1980; 121: 339-342.

13. Collins DV, Cutillo AG, Armstong JD, et al. Large airway size, lung size, and maximal expiratory flow in healthy non smokers. Am Rev Respir Dis 1986; 134: 951-955.

14. Jesseph JE, Merendino KA. The dimensional interrelationships of the major components of the human tracheobronchial tree. Surg Gynecol Obstet 1957; 105: 210-214. 
15. Dolyniuk MV, Fahey PJ. Relationship of tracheal size to maximal expiratory airflow and density dependence. J Appl Physiol 1986; 60: 501-505.

16. Breatnach E, Abbott GC, Fraser RG. Dimensions of the normal human trachea. AJR 1984; 141: 903-906.

17. Mansell AL, Bryan AC, Levison M. Relationship of lung recoil to lung volume and maximum expiratory flow in normal children. J Appl Physiol 1977; 42: 817823.

18. Zapletal A, Motoyama E.K, Van De Woestijne KP, Hunt VR, Bouhuys A. Maximum expiratory flow-volume curves and airway conductance in children and adolescents. J Appl Physiol 1969; 26: 308-316.

19. Hoffstein V. Relationship between lung volume, maximal expiratory flow, forced expiratory volume in one second and tracheal area in normal men and women. Am Rev Respir Dis 1986; 134: 956-961.

20. Miller RD, Hyatt RE. Evaluation of obstructing lesions of the trachea and larynx by flow-volume loops. Am Rev Respir Dis 1973; 108: 475-481.

21. Quanjer PH, (ed.). Standardized lung function testing: report of working party on "standardization of lung func tion tests". Bull Eur Physiopathol Respir 1983; 19 (Suppl. 5): 1-95.

22. Official Statement of the European Respiratory Society. Standardized lung function testing. Eur Respir J 1993; 6 (Suppl.16): 5-100.

23. Amrein R, Keller R, Joos H, Herzog H. Neue Normalwerte fuer die Lungenfunktionspruefung mit den
Ganzkoerper-plethysmographie. Dtsch Med Wschr 1969; 94: 1785-1893.

24. Griscom NT. CT-measurement of the tracheal lumen in children and adolescents. AJR 1991; 156: 371-372.

25. Griscom NT, Wol MEB. Dimensions of the growing trachea related to age and gender. AJR; 1986; 146: 233-237.

26. Empey W. Assessment of upper airway obstruction. $\mathrm{Br}$ Med J 1972; 3: 503-505.

27. Miller MR, Pincock AC, Oates GD, Wilkinson R, Skenesmith $\mathrm{H}$. Upper airway obstruction due to goitre: detection, prevalence and results of surgical management. Q J Med 1990; 274: 177-188.

28. Fouke JM, Strohl KP. Effect of position and lung volume on upper airway geometry. J Appl Physiol 1987; 63: $375-378$.

29. Shepard JW, Stanson AW, Sheedy PF, Westbrook PR. Fast-CT evaluation of the upper airway during wakefulness in patients with obstructive sleep apnoe. In: Sleep and Respiration. Wiley-Liss, Inc., 1990; pp. 273-282.

30. Ell SR, Jolles H, Galvin JR. Cine CT demonstration of nonfixed upper airway obstruction. AJR 1986; 146: 669-677.

31. Brooks LJ, Castile RG, Glass GM, et al. Reproducibility and accuracy of airway area by acoustic reflection. $J$ Appl Physiol 1984; 3: 777-787.

32. Brooks LJ, Byard PJ, Fouke JM, Strohl KP. Reproducibility of measurements of upper airway area by acoustic reflection. J Appl Physiol 1989; 66: 2901-2905. 